\title{
"Cidadãos teóricos de uma nação imprecisa": a ação política de estrangeiros no reinado de D. Miguel, 1828-1834
}

Andréa Lisly Gonçalves ${ }^{[1]}$

\section{Resumo}

O reinado de D. Miguel (1828-1834) colocou fim à primeira experiência liberal portuguesa e foi marcado por intensa repressão política aos seus opositores. Contra o rei absoluto formou-se uma verdadeira "internacional antimiguelista”, que incluía militantes do Brasil, da América Hispânica, da Espanha, da Itália, entre outros países. Tendo como fonte principal os processos políticos do Reinado de D. Miguel, depositados no Arquivo Nacional da Torre do Tombo, em Lisboa, este artigo pretende esclarecer o trânsito de pessoas e de ideias, ressaltando os contrastes existentes entre os contextos americano e europeu.

Palavras-chave: liberalismo; absolutismo; miguelismo.

\section{“Ciudadanos teóricos de una nación imprecisa ": la acción política de extranjeros en el reinado de D. Miguel, 1828-1834}

\section{Resumen}

El reinado de D. Miguel (1828- 1834) puso fin a la primera experiencia liberal portuguesa y fue marcado por una intensa represión política a sus opositores. Contra el rey absoluto se formó una verdadera “internacional antimiguelista” , que incluía militantes de Brasil , de Hispanoamérica, de España, de Italia, entre otros países. Teniendo como fuente principal los procesos políticos del Reinado de D. Miguel , depositados en el “Arquivo Nacional da Torre do Tombo", en Lisboa, este artículo pretende aclarar el tránsito de personas y de ideas , resaltando los contrastes existentes entre los contextos americano y europeo.

Palabras clave: liberalismo, absolutismo, miguelismo.

"Citizens in theory of a nebulous nation": the political action of foreigners during Dom Miguel's reign, 1822-1834

\section{Abstract}

The reign of D. Miguel (1828-1834) brought an end to the first Portuguese liberal experiment and was marked by an intense political repression against its opponents. A veritable "antimiguelist international" was organized to confront the absolute monarch, congregating militants from Brazil, Hispanic America, Spain and Italy, among other countries. Drawing, as its main source, from the political proceedings of D. Miguel's reign deposited at the National Archives of Torre do Tombo, in Lisbon, this paper aims at elucidating the transit of people and ideas, stressing the contrasts existing between the American and European contexts.

Key words: liberalism; absolutism; miguelism.

\section{“Citoyens théoriques d'une nation imprécise": l'action politique des étrangers dans le royaume de D. Miguel,} 1828-1834.

\section{Résumé}

Le royaume de D. Miguel (1828-1834) a mis fin à la première expérience libérale portugaise et a été marqué par une répression politique intense à ses opposants. Il s'est formé, contre le roi absolu, un véritable anti-miguelisme international, constitué par des militants du Brésil, de l'Amérique hispanique, de l'Espagne, de l'Italie, et d'autres pays. Ayant comme source principale les procès politiques du Royaume de D. Miguel, qui se trouvent aux Archives Nationales « Torre do Tombo », à Lisbonne, cet article vise à jeter une lumière sur la circulation des personnes et des idées dans cette période, en mettant en valeur les contrastes existants entre les contextes américain et européen.

Mots-clés: libéralisme, absolutisme, miguelisme. 


\section{Introdução}

$\mathrm{H}$

á alguns anos, venho estudando a história dos brasileiros implicados nos processos políticos instaurados no reinado de D. Miguel, em Portugal, entre 1828 e 1834 (Gonçalves, 2013, p.211-234; 2012, p.32-55).

Acusados de conspirarem contra o rei usurpador, de defenderem o retorno da Carta Constitucional e de combaterem o retorno do absolutismo em Portugal, os presos políticos brasileiros do regime miguelista não compunham um grupo socialmente coeso. Ainda que predominassem os militares, estiveram envolvidas pessoas de diferentes condições sociais: cirurgiões, estudantes, criados de servir. Brasileiros que entoavam cantos e hinos a favor da constituição; que distribuíam e liam panfletos em locais públicos. Todos constitucionalistas ou acusados de defenderem o liberalismo.

A participação de brasileiros na "militância antimiguelista" pode ser compreendida, pelo menos a princípio, pelos laços que uniam Brasil e Portugal, mesmo nos anos que se seguiram à emancipação da ex-colônia portuguesa na América. Afinal, tratava-se do processo de superação do império luso-brasileiro, ideado pelos governantes portugueses, sobretudo a partir de 1790, tendo como figura destacada D. Rodrigo de Sousa Coutinho, o secretário de Estado dos Negócios da Marinha e Domínios Ultramarinos do regente D. João. Já a oposição feita por homens de outras nacionalidades ${ }^{1}$ às forças que compunham o reinado de D. Miguel sugere chaves explicativas diferenciadas daquelas que podem esclarecer o envolvimento de brasileiros nas lutas contra o miguelismo.

Em um contexto de restaurações como o europeu das primeiras décadas do século XIX, o exame da documentação de processados políticos provenientes de regiões que não as do Império Português pode trazer algum esclarecimento sobre o trânsito de ideias e de projetos políticos no interior da Europa e nas Américas.

A pesquisa sobre os brasileiros que se opuseram ao regime implantado por D. Miguel, principalmente no período anterior ao fim ao seu reinado, já se encontra avançada. A da participação de estrangeiros, porém, apenas muito recentemente tem sido alvo de meus estudos. Assim, neste artigo, serão tratados apenas alguns dados preliminares sobre essa participação.

De início, abordarei aspectos da conjuntura econômica e política de Portugal no período em que D. Miguel assume o poder. Em seguida, tratarei o tema das relações entre Espanha e Portugal nas décadas iniciais do Oitocentos, situando-as no contexto da Europa restaurada e da oposição liberal que reunia constitucionalistas das mais diferentes partes do mundo. Por fim, me ocuparei dos estrangeiros que foram processados em Lisboa durante o reinado de D. Miguel.

${ }^{1}$ Ressalve-se que o termo nacionalidades é utilizado aqui reconhecendo sua imprecisão em um contexto de formação dos Estados Nacionais Modernos, tema que será abordado nas seções finais deste artigo. 


\section{O anjo exterminador da Constituição}

Se os anos finais da década de 1810 foram de retomada do crescimento da economia portuguesa, reconstruída após a expulsão, em 1815, das tropas francesas, os anos 1820 terminaram em uma profunda crise. A esse respeito, não podiam ser mais eloquentes os dados do comércio exterior que incluem "nações estrangeiras", o Brasil e as colônias:

Tabela 1 - Dados do comércio exterior: Portugal, 1815-1828

\begin{tabular}{cccc} 
& $\begin{array}{c}\text { Importação } \\
\text { (média anual) }\end{array}$ & $\begin{array}{c}\text { Exportação } \\
(\text { média anual) }\end{array}$ & $\begin{array}{c}\text { Total } \\
\text { (média anual) }\end{array}$ \\
\hline $1815-1819$ & $30.234 .640 \$ 000$ & $27.036 .960 \$ 000$ & $57.271 .600 \$ 000$ \\
\hline $1820-1823$ & $18.181,935 \$ 000$ & $13.014 .175 \$ 000$ & $31.196 .110 \$ 000$ \\
\hline $1824-1828$ & $15.615,460 \$ 000$ & $12.359 .800 \$ 00$ & $27.975 .260 \$ 000$ \\
\hline
\end{tabular}

Fonte: Cascão (1985, p.119)

Aos dados, constituídos a partir das Balanças do Comércio, o autor acrescenta que a "situação é ainda menos lisonjeira quando se conclui que o montante do comércio com o Brasil e as colônias nos anos de 1824-1828 representa só 38,1\% do observado em 1815-1819" (Cascão, 1985, p.120). As finanças do Estado encontravam-se reduzidas a $62 \%$ de suas receitas de 1808, uma situação falimentar (Ramos, Sousa e Monteiro, 2009, p.481).

O pequeno movimento de barcos, principalmente os estrangeiros, era apenas um dos desdobramentos da crise política que se instalou no país, pelo menos desde 1826, ano da morte de D. João VI. As contendas acirraram-se, sobretudo, porque o rei morto não deixara qualquer instrução sobre sua sucessão. Na disputa, enfrentavam-se D. Pedro I, imperador do Brasil, e o seu irmão mais moço, D. Miguel. Como solução de compromisso, o primeiro imperador do Brasil abdicaria do trono português em favor de sua filha, D. Maria da Glória (1819-1853), e continuaria reinando na ex-América Portuguesa. Em seguida, realizar-se-ia o casamento entre a sobrinha e o tio que, só então, ocuparia o trono. A exigência maior era a de que o regime político fosse a monarquia constitucional, aliás, com uma constituição outorgada pelo próprio D. Pedro, cópia da brasileira, apenas adaptada ao Reino.

Que D. Miguel não parecia disposto a cumprir o acordo constatou-se em sua própria relutância em jurar a constituição. O enlace matrimonial não ocorreu. Em vez disso, no ano de 1828, com o apoio da mais alta nobreza e do alto clero, D. Miguel usurpou o Trono e tornou-se rei de Portugal. Nas palavras de José Saldanha Oliveira Daun, um contemporâneo, D. Miguel foi o "Anjo exterminador da constituição".

Ainda que D. Miguel só viesse a assumir o Trono em 1828, boa parte da historiografia portuguesa não parece colocar em questão que o ano de 1823 marca o fim da primeira experiência liberal portuguesa (Hespanha, 2004; Lousada, 
1987). Naquele ano, o movimento conhecido como Vila-Francada ${ }^{2}$ resultou no fechamento das Cortes por D. João VI sob o pretexto da convocação de uma constituinte, sempre adiada e que não se cumpriu. Assim, no período que vai de 1823 a 1826, ano da morte de D. João VI, Portugal esteve marcado pela revogação da constituição "tida como subversiva e insubsistente" (Hespanha, 2004, p.153), a que se seguiram "medidas restauracionistas e retaliatórias", retomando-se os "estilos e formas legislativas do absolutismo". Entre outras medidas, restauraram-se as comunidades religiosas suprimidas em 1822, com a respectiva devolução dos bens, assistindo-se ao retorno das tradicionais ordenanças, com a dissolução da Guarda Nacional e a introdução das "legiões nacionais" (Hespanha, 2004, p.154).

A imprensa realista, ao traduzir as ações de D. João VI, não tinha dúvidas de que seu retorno tinha por objetivo restaurar o poder do Trono e do Altar e, quem sabe, com isso, preservar a monarquia luso-brasileira:

O Senhor D. João VI, de gloriosa memória, quando partiu do Rio de Janeiro para Portugal, para o salvar da Revolução de 1820 (ação que só por si bastava para fazer eterna a gratidão dos verdadeiros portugueses) deixou na mesma Corte, e Reino do Brasil, ao Senhor D. Pedro seu Augusto Filho, como Regente do mesmo Estado, que fazia uma parte integrante da Monarquia. ${ }^{3}$

A constatação de que os miguelistas não puderam prescindir de instrumentos "modernos" na execução de suas políticas contribuiu para dividir as opiniões sobre a natureza absolutista de sua atuação política, desde os golpes por eles intentados a partir de 1823. Um bom exemplo é o da imprensa periódica.

No reinado de D. Miguel, a edição de periódicos foi uma atividade das mais intensas. Há que ressaltar, porém, que os jornais estavam sujeitos à forte censura, não havendo espaço para a imprensa liberal. Essa, ao contrário e à exceção dos exilados, que publicavam no exterior, teria de recorrer à tradição absolutista de se manifestar através de panfletos e pasquins anônimos.

Porém, enganam-se os que supõem que o elitismo do regime, conhecido como miguelismo, afastou o apoio dos setores populares. Ao contrário, uma parcela da população mais pobre de várias regiões do Reino, erradios, homens solteiros pobres, apoiou ativamente o novo regime e travou uma longa guerra de guerrilhas contra os liberais, cujo apoio popular vinha de artesãos, camponeses e pequenos comerciantes.

\footnotetext{
${ }^{2}$ Ainda que, tal como étradicionalmente apresentada, a Vila-Francada seja, na sua origem, um pronunciamento militar contrarrevolucionário liderado por D. Miguel, tratou-se de um golpe ambíguo no qual se sobrepuseram dois golpes de Estado (o de D. Miguel e o de D. João VI) e acabou por se transformar em uma coalisão de liberais moderados e partidários da monarquia tradicional. Lousada e Ferreira (2009, p.50.) Para alguns autores, a atitude do rei foi de contemporização. A nomeação de D. Miguel comandante do exército, em Vila Franca, ato explícito do apoio de D. João ao movimento contrarrevolucionário encabeçado por seu filho mais moço, seria compensada pela disposição real em outorgar uma nova constituição ao país. Pedreira e Costa (2006, p.18.) Em ambas as interpretações, porém, prevalece a ideia de que a atitude de D. João VI foi "hesitante".

${ }^{3}$ Grifo da autora deste artigo. Periódico para os bons realistas. Jornal Histórico, político e noticioso, n. 1, terçafeira, 10 jun. 1828. Na nova Impressão Silviana. Ano de 1828. Com licença. Travessa da Portaria das Freiras de Santa Ana, p.3.
} 
As mobilizações populares, no contexto do miguelismo teriam um forte componente patriótico. ${ }^{4}$ Para esses setores, a adesão a D. Miguel justificava-se pelo combate às pressões estrangeiras sobre Portugal, viessem elas do Brasil, da Inglaterra ou da França. O miguelista Aires Pinto de Sousa ${ }^{5}$ deixou registrado em um ofício o que ele considerava as principais características do reinado de D. Miguel. Ao lado da constatação de que as forças militares encontravam resistência para conter os levantes liberais e da opinião de que apenas os "díscolos", os "cismáticos", não queriam a aclamação do irmão mais moço de D. Pedro, ressaltava a "componente patriótica das ações populares, pois a elas parece que a ordem de coisas é fruto da pressão estrangeira".

As mobilizações populares em Portugal, de apoio ao projeto da contrarrevolução, assumiram proporções significativas. Não resta dúvida de que se tratou de um regime político mobilizador, mesmo com a ressalva de que a natureza, a origem e o superdimensionamento do número de adeptos das classes ínfimas a D. Miguel vieram a ser uma criação de memorialistas e historiadores liberais, mais ou menos contemporâneos dos acontecimentos, com o objetivo de "desqualificar" o inimigo ${ }^{7}$. De acordo com Maria de Fátima Sá, as dúvidas sobre a legitimidade dinástica do infante, tanto no plano internacional quanto no plano interno, ajudariam a explicar os traços de modernidade do regime, um fator que, somado ao seu caráter mobilizador, "têm justificado inclusivamente o paralelismo com regimes (...) de direita do século XX" (Ferreira, 2002).

Tudo isso não quer dizer que a historiografia portuguesa, sobretudo a contemporânea, não esteja ciente de que as opções políticas não traduziam, simplesmente, as situações sociais, o que não significa que se tenha zabandonado a tentativa de estabelecer alguma regularidade entre alinhamento político e origem social; e mais, que não haja divergências nas análises empreendidas com esse objetivo.

É o caso, por exemplo, da definição da origem social dos partidários da contrarrevolução no que diz respeito às classes superiores. Há aqueles que defendem que "O constitucionalismo dividiu as elites da sociedade portuguesa, na corte e na província” (Ferreira, 2002, p.483). Outros, que as grandes casas titulares e o alto clero compunham com os miguelistas (Lousada, 1987; Lousada e Ferreira, 2009).

\footnotetext{
4“Em Espanha e Portugal [do século XIX] (...) em nome de um patriotismo mediado pela fidelidade à aliança entre o trono e o altar, ocorrem levantes populares." Catroga (2010, p.43).

$5^{5} \mathrm{O}$ brigadeiro Pinto de Sousa fora governador das justiças do Porto e exonerado do cargo na regência de Isabel Maria [1826-1828]. O governo de D. Miguel restituiu-o ao lugar e no dia 16 de abril [de 1828] voltou ao Porto." Lousada e Ferreira (2009, p.148).

${ }^{6}$ Ofício de Aires Pinto de Sousa para o ministro do Reino, Porto, 27 de abril de 1828. Lousada e Ferreira (2009, p.148).

־Linz (1980). O autor distingue os regimes autoritários dos totalitários, entre outros critérios, pelo caráter mobilizador do grupo no poder no caso do totalitarismo. Ou seja, enquanto nos regimes ditatoriais a expectativa é de que o apoio da população ao governo seja tácito, nos totalitários, a adesão deve ser explícita, pública e coletiva. Com isso, não se quer afirmar que o regime instaurado por D. Miguel possa ser caracterizado como totalitário. Porém, parece se aproximar de uma solução desse tipo, inclusive se se considera a quantidade de símbolos adotados pelos partidários do regime e que implicavam a reunião de multidões para "celebrar" o regime.
} 
Para alguns publicistas, o clero foi o responsável pela mobilização dos setores ínfimos. Afinal, "Foram os hábitos, as roupetas, e os homens de réo-réo do canto-chão, que deram os conselhos, que facilitaram o dinheiro, que fanatizaram o povo, e arranjaram o exército que sustentava D. Miguel". A passagem, excerto de uma brochura publicada no estilo epistolar, foi escrita por Valentim Marcellino dos Santos, formado em direito pela Universidade de Coimbra. Antimiguelista, participou ativamente das disputas que se instalaram entre os liberais após a deposição de D. Miguel. ${ }^{8}$

Para muitos estudiosos, o reinado de D. Miguel foi um governo de terror. Calcula-se que, em uma população de 3 milhões de habitantes, foram feitas cerca de 13 mil prisões (as quais, somente em Lisboa, resultaram em torno de 1.400 processos). ${ }^{9}$

\section{Portugal e Espanha}

Wilma Peres Costa, em seu artigo "Entre tempos e mundos: Chateaubriand e a outra América", aponta uma série de considerações ao tema da emergência dos Estados Nacionais na Espanha, em Portugal, no Brasil e na América Hispânica (Costa, 2010, p.5-25).

Depois de indicar as especificidades do processo em um e outro continente, a autora afirma que, no caso das metrópoles ibéricas, o que se observou foi a sua periferização. Na raiz da posição secundária assumida por Portugal e pela Espanha no cenário europeu estaria exatamente a perda de suas colônias no Novo Mundo. A abordagem do assunto mostra o quanto estão imbricadas, na península, a crise, inclusive a econômica, e a emergência de propostas e de práticas que acalentam o retorno à antiga ordem. A autora ajuda a esclarecer, também, as dificuldades de recomposição do Império, existentes após o surgimento dos Estados Nacionais: "Nas emergentes nações americanas os termos passam a operar em registros opostos - a afirmação da condição nacional emergindo do rompimento com a condição de colônia, suplantando significados anteriormente vigentes que incorporavam" (Costa, 2010, p.4).

A crise dos sistemas imperiais ibéricos ${ }^{10}$ e razões de ordem histórica irão aproximar Portugal e Espanha. A aproximação dar-se-á tanto no que diz respeito aos projetos de retorno à antiga ordem quanto àqueles de feição liberal.

\footnotetext{
${ }^{8}$ CARTAS de Valentim Marcellino dos Santos ao Sr. Francisco Jerônimo da Silva acerca da Archi-confraria do Santíssimo Coração de Maria. Porto Typografia de Sousa \& Faria. Rua Nova do Almada, n. 139, s.d. Biblioteca Geral da Universidade de Coimbra.

${ }^{9} \mathrm{O}$ que não significa dizer que todos os processados eram moradores de Lisboa. As proveniências eram variadas. Em trabalho futuro, pretende-se traçar uma "geografia” correlacionando o local de habitação e o da ação política dos acusados.

10“Também a Espanha perdeu as colônias americanas, com exceção de Cuba, entre 1815 e 1824. Crise econômica e crise financeira tornavam patente a necessidade de grandes reformas, a base do Antigo Regime encontrava-se irremediavelmente abalada com a ruptura do pacto americano. A consciência e a aceitação do caráter irreversível da ruptura do pacto colonial foi, porém, lenta nos dois países peninsulares, Portugal só reconheceria o Brasil independente em 1825, sob forte pressão inglesa. O regresso ao absolutismo viera, entretanto, interromper as reformas durante uma década em ambos os países." Pereira (2012, p.79-80).
} 
A conjuntura política instável dos dois países, comum a grande parte dos contextos históricos de formação dos Estados Nacionais Modernos, promoveu o trânsito tanto de realistas quanto de liberais entre Espanha e Portugal.

$\mathrm{O}$ vintismo, desencadeado no Porto no mês de agosto, esteve intimamente relacionado ao movimento constitucionalista espanhol, iniciado com a Revolução de Cádiz. A troca de experiência entre a militância liberal, nos dois lados da fronteira, manifestou-se na propaganda política, no apoio tático, na criação de lojas maçônicas, sendo marcante a cooperação espanhola nesse processo. Dava mostras dessa cooperação a existência de cerca de 200 exemplares, apenas em Lisboa, da edição da constituição gaditana. O texto da constituição de Cádiz foi tão incessantemente invocado que coube a um parlamentar português, Manuel Fernandes Tomás, lembrar aos demais membros das Cortes que o objetivo era elaborar uma "constituição portuguesa, não espanhola" (Pereira, 2012, p.75).

Porém, conforme já observado, no período que vai de 1823 a 1826, ano da morte de D. João VI, Portugal viu-se marcado pela revogação da constituição e pelo retorno ao absolutismo.

\section{As mobilizações populares em Portugal, de apoio ao projeto da contrarrevolução, assumiram proporções significativas}

Nesse ponto, é necessário um parêntese. Ainda que se esteja admitindo que os ultrarrealistas, nos dois países, militassem pelo retorno à antiga ordem, cabe aqui nos referirmos ao conceito de retradicionalização. É Clifford Geertz (1998, p.124), evocando Karl Mannheim (1953), quem melhor elucida o fenômeno histórico que o conceito ilumina. Para esse autor, não haveria contradição no fato de as ideologias formais, como ele chama as que surgem em contextos de crise e buscam apontar a direção, "desejarem impor (...) um revigoramento dos costumes, ou reimpor a hegemonia religiosa". Segundo ele, em sua leitura de Mannheim, "só se constroem argumentos para a tradição quando suas credenciais foram questionadas. Na medida em que tais apelos são bem-sucedidos, eles trazem de volta não um tradicionalismo ingênuo, mas uma retradicionalização ideológica - algo totalmente diferente".

O caráter moderno e arcaico do reinado de D. Miguel indicava, não a volta à antiga ordem, mas um momento em que a tradição havia sido, talvez, mais que questionada. Não era o caso de defesa de um "tradicionalismo ingênuo", mas de um processo claro de retradicionalização ideológica. ${ }^{11}$

\footnotetext{
"O conceito de retradicionalização se aproxima do de contrarrevolução, da maneira como é apresentado por Jordi Canal. Referindo-se ao carlismo na Espanha, Canal afirma que: "La contrarevolución, tanto a nível del pensamiento como en el da la acción, constituía una reación ante la revolucción, más o menos real, más o menos imaginaria con que llega a establecer una relación dialéctica, condicionando las evoluciones tanto de una como de la otra. Una reacción que, de todas maneras, no significaba una simple vuelta al Antiguo Régimen, sino que contaba con una ideologia y un proyecto social propios". Canal (2005, p.49-50).
} 
A volta de Fernando VII ao trono, em 1823, com a decisiva participação francesa, deliberada no Congresso de Verona, fez do território espanhol o refúgio privilegiado para os aliados de D. Miguel, sobretudo os da tropa que participou dos sucessivos golpes intentados pelo infante, iniciados com a VilaFrancada, também em 1823 (Pereira, 2012). Com o apoio do rei, os rebeldes miguelistas promoviam, a partir do território espanhol, incursões em território lusitano que se mostrariam decisivas para a sustentação das pretensões de D. Miguel ao trono português. Pelo menos 6.000 miguelistas encontravam-se exilados na Espanha, cálculo a que se chega a partir das informações sobre a fracassada incursão armada com um corpo luso-espanhol, entre novembro de 1826 e janeiro de 1827, na sequência das revoltas do Norte de Portugal (Pereira, 2012, p.82).

Os golpes sofridos pelo constitucionalismo na Península Ibérica, no primeiro lustro da década de 1820, assim como a recusa ao apoio popular mais radical às suas propostas, manifestado nas "guerrilhas de Madri", explicam, pelo menos em parte, o entusiasmo de liberais lusitanos e hispânicos, sobretudo os moderados, em torno da Carta outorgada por D. Pedro I, a Portugal, em 1826. ${ }^{12}$ Fruto da adaptação da carta também outorgada pelo imperador ao Brasil, em 1824, após o fechamento da Assembleia Constituinte que se reunira no Rio de janeiro um ano antes, a Carta de 1826 foi recebida com muito interesse, principalmente pelos espanhóis moderados que se encontravam no exílio.

Em Londres, muitos deles se reuniam em torno do Jornal Ocios de Españoles Emigrados, publicado entre 1824 e 1827. Em seu número de outubro de 1826, os editores do periódico "dedicavam fervorosos elogios" à Carta outorgada. Tanto as lideranças liberais moderadas quanto as exaltadas chegaram a propor D. Pedro I como rei de Espanha sob o argumento de que, por ser filho de D. Carlota Joaquina, irmã de Fernando VII, estaria, assim, respeitada a sucessão dinástica (Suanzes-Carpegna, 2010, p.237-274).

Em decorrência disso, "em 1828, criou-se em Londres um 'Clube HispanoLusitano, que agrupava exilados dos dois países com o propósito de restaurar neles o Estado constitucional, mediante uma monarquia liderada por D. Pedro" (Suanzes-Carpegna, 2010, p.259).

Toda a mobilização no interior dos dois países desenvolveu-se no contexto de um amplo movimento liberal europeu. A Assembleia de Constitucionais Europeus foi uma das mais importantes sociedades secretas, à qual pertenciam espanhóis, portugueses, italianos, franceses, ingleses e ibero-americanos. ${ }^{13}$ Também para esses liberais europeus, a figura de D. Pedro IV vai aparecer como uma possibilidade de se estabelecer uma monarquia liberal ibérica. $\mathrm{O}$ imperador do Brasil começou a receber mensagens nesse sentido desde 1826.

\footnotetext{
12Sobre a constituição portuguesa de 1826, ver: Paquete (2011, p.444-471).

13“Solidariedades de várias origens nacionais já na década de 20 exprimiam a dimensão internacional do liberalismo europeu, como o general inglês Wilson que apoiou os revolucionários, particularmente de Portugal e Espanha, e foi condecorado com o título de comendador da ordem da Torre e Espada pelo governo português. Giuseppe Pepe, general napolitano, viria a refugiar-se em Portugal fracassada a tentativa revolucionária em Nápoles." Pereira (2012, p.87, nota 53).
} 
A proposta perdurou até o ano de 1833, quando a morte de Fernando VII forçou o reposicionamento dos liberais em apoio a Dona Isabel, contra a ofensiva absolutista, representada pelo carlismo. ${ }^{14}$

Quanto a D. Miguel, além de contar com o apoio de boa parte da nobreza e do clero, o regime por ele implantado, conforme mencionado anteriormente, mobilizou amplos setores da população, principalmente aqueles menos enraizados socialmente. No que diz respeito a D. Carlos, que, do território português, sob os auspícios de D. Miguel, travava uma guerra de guerrilhas, chegando a ocupar certas regiões da Espanha, sem nunca alcançar o poder, o apoio popular, predominantemente o de camponeses, parece ter sido inferior ao registrado para o miguelismo. ${ }^{15}$

As informações apresentadas na próxima seção deste artigo não possibilitam que se contribua para o debate sobre a maior ou menor extensão do apoio popular ao carlismo, mesmo que consideremos apenas os espanhóis e os galegos. Apesar de boa parte dos incriminados exercer ocupações que revelam baixa extração social, como boleeiros, aguadeiros, padeiros, caixeiros e, principalmente, criados de servir, não se trata de uma amostra significativa do ponto de vista quantitativo, apontando apenas a presença dos setores populares no campo oposto ao da contrarrevolução. Mas os dados permitem que se conheçam fragmentos da história de pessoas provenientes de regiões da Europa e das Américas que, em Portugal, foram processadas, em sua maioria, sob a acusação de serem liberais e constitucionalistas.

\section{A "internacional antimiguelista"}

Estabelecer a origem dos estrangeiros que aparecem nos processos políticos do reinado de D. Miguel apresenta inúmeros desafios teóricos e metodológicos. O principal deles, parece-me, é o risco de tratar as nacionalidades com a perspectiva que temos hoje, projetando uma realidade estranha ao contexto das primeiras décadas do século XIX, uma prática presente até bem pouco tempo na historiografia. Nas palavras de François-Xavier Guerra:

\begin{abstract}
En pocas épocas y lugares la distorsión entre lo que vivieran los protagonistas y el significado que se le atribuyó después es tan considerable como en la América del período en estúdio [18081830]. Obsesionada por legitimar la existencia de la nación, la historiografia pátria ha tendido desde muy pronto a considerar esta época como un bloque, como una marcha ineluctable hacia la independência y la modernidade política. (Guerra, 2007, p.429-447)
\end{abstract}

\footnotetext{
${ }^{14} \mathrm{O}$ assunto é tema da obra: Brancato (2014).

${ }^{15}$ Rújula (1994, p.126). Nesse artigo, o autor levanta alguns questionamentos sobre a real abrangência do apoio popular ao carlismo, ressaltando o caráter compulsório do recrutamento dos "voluntários" carlistas e apontando a ausência de estudos mais sistemáticos sobre o tema.
} 
A noção de pertencimento a uma comunidade imaginada, ${ }^{16}$ tanto na América, quanto na Europa, encontrava-se em gestação, com avanços maiores ou menores, dependendo da região. Na ibero-américa, por exemplo, até bem próximo aos processos de independência, as principais lideranças políticas viam-se como partes integrantes fossem da nação portuguesa, fossem da nação espanhola.

A situação altera-se na conjuntura acelerada da expansão napoleônica. Mas o ponto de inflexão dar-se-á mesmo com as disputas entre coloniais e metropolitanos nos processos constituintes que apontavam o limite da integração dos representantes da América naquelas assembleias.

Outro exemplo, que mostra a complexidade do assunto tratado, é o aparecimento de soluções como a da "União Ibérica" em torno da constituição portuguesa de 1826 e de D. Pedro I, acalentada por uma corrente liberal representada por exilados políticos dos dois países, assunto citado logo acima. O arranjo mesclava projetos políticos do tipo imperial, ainda que prevalecesse a autonomia das partes, com a nova realidade dos Estados liberais e de uma monarquia constitucional.

\section{Na ibero-américa, até bem próximo aos processos de independência, as principais lideranças políticas viam-se como partes integrantes fossem da nação portuguesa, fossem da nação espanhola}

No ponto em que se encontra a pesquisa, não é possível elucidar a maior parte das questões levantadas, mas é importante formulá-las e lembrar que elas são suscitadas tanto pela historiografia quanto pela própria documentação.

Os dados apresentados em seguida foram sistematizados a partir da consulta ao catálogo da documentação existente no Arquivo Nacional da Torre do Tombo, em Portugal. O catálogo traz informações detalhadas sobre os processos, reproduzindo, em geral, sua abertura, contendo os dados sobre naturalidade, ocupação, estado civil, filiação, com algumas exceções. ${ }^{17}$ Sobre os processos, propriamente, apenas os que envolvem brasileiros foram consultados, lidos e analisados. Em alguns deles, havia mais de um implicado que não fosse de Portugal e do Brasil.

Os Processos políticos do reinado de D. Miguel encontram-se no Fundo dos feitos findos do Arquivo Nacional da Torre do Tombo (ANTT). Em 15 de agosto de 1828, o governo de D. Miguel instituiu, na Casa de Suplicação, uma "Comissão para julgar todos os crimes cometidos contra a Real Pessoa de El Rei... contra a Segurança do Estado". Essa comissão era composta por um juiz relator e por nove juízes adjuntos. Trata-se de 1.402 processos, abertos em Lisboa, a maioria envolvendo mais de um implicado, o que dificulta estabelecer o número exato dos opositores do regime que foram processados na capital do Reino.

${ }^{6}$ Sobre o conceito, ver: Anderson (2008)

${ }^{17}$ O catálogo foi reproduzido por Lima (1972). As referências apresentadas no livro foram checadas com as "cadernetas" disponíveis no ANTT. Não se observou qualquer discrepância. 
Antes de tudo, é importante esclarecer que há presos relacionados cujas informações sobre a naturalidade são imprecisas. Optou-se, assim, por excluílos das listas que compõem os quadros. Um exemplo pode ser citado: o de pessoas identificadas como naturais de Portugal, mas que foram julgadas pela Conservatória de outros países.

Em janeiro de 1776, foi criado um Juízo para julgar causas de negociantes estrangeiros, domiciliados ou não em Portugal, presidido por um conservador e que contava com juízes e escrivães próprios. ${ }^{18}$ Pelo que se depreende da documentação, a competência desses tribunais estendia-se aos filhos de estrangeiros, nascidos em solo português. Seria esse o caso de Timóteo Matias Osternold, ex-mestre de música do Regimento de Infantaria n. 16, natural de Sintra, filho de Matias Osternold e de Leonor Osternold, preso sob a denúncia de ser partidário do regime liberal. A sentença contra Timóteo Matias foi proferida pelo juiz conservador da Nação Alemã que o "condenara ao tempo de prisão sofrida". ${ }^{19}$

Ainda que se tenha procurado elucidar, na seção anterior, aspectos da conjuntura política da Península Ibérica nas décadas iniciais do Oitocentos, abordando o trânsito de ideias e de pessoas, só será possível apontar, em trabalhos futuros, como se pretende, os vínculos entre a naturalidade, a defesa de ideias liberais e a luta contra o absolutismo, até porque alguns desses "conspiradores" poderiam ter um enraizamento na nação portuguesa que tornaria indiferente sua proveniência estrangeira. Supomos, porém, que não seja o caso daqueles que foram expulsos de Portugal e obrigados a retornarem à sua terra natal.

Apesar dessas ressalvas, parece-me que identificar personagens que, com graus diferentes de envolvimento, lutaram contra o regime absolutista de D. Miguel e puseram-se, muitos deles, em defesa do constitucionalismo, pode contribuir para o entendimento da formação das nações modernas, sob o enfoque, ainda que não exclusivamente, de pessoas "comuns" ${ }^{20}$ e não apenas daquelas que já haviam se projetado na política oficial. Em razão disso, optou-se por destacar, no âmbito do tema principal proposto - o das nacionalidades dos presos processados - , a ocupação dos estrangeiros encontrados na documentação pesquisada.

Objetivo semelhante moveu o bacharel Pedro da Fonseca Serrão Veloso. Decorridos cinco anos da Revolução do Porto de 1828, sufocada pelas tropas de D. Miguel, Serrão Veloso ofereceu a D. Pedro IV uma publicação contendo várias listas com nomes de pessoas que foram pronunciadas após a vitória das tropas realistas. ${ }^{21}$ Da relação constam lavradores, músicos, criados de servir.

\footnotetext{
${ }^{18}$ As conservatórias foram extintas em 1845. Arquivo Nacional Torre do Tombo. Recuperado da internet: http:// digitarq.arquivos.pt/details?id=3908401.

${ }^{19}$ ANTT, Maço 80, n. 1.

20Burke (2009, p.11). Em seu estudo sobre a Europa Moderna, o autor utiliza a categoria povo comum para designar o "conjunto da não elite, incluindo mulheres, crianças, pastores, marinheiros, mendigos e os demais grupos sociais"

${ }^{21}$ COLEÇÃO de listas que contém os nomes das pessoas que ficaram pronunciadas e sumários a que mandou proceder o Governo Usurpador depois da heroica contrarrevolução que arrebentou na mui nobre cidade do Porto em 16 de maio de 1828, nas quais se faz menção do destino que a Alçada, criada pelo mesmo governo para as julgar, deu a cada uma delas, Porto: Tipografia de Viúva Álvares Ribeiro \& Filho, 1833. Alguns dos pronunciados pela Alçada do Porto foram processados em Lisboa, como foi o caso do brasileiro de Vila Rica, Jerônimo Pereira de Vasconcelos. ANTT, Maço 33, número 12.
} 
Assim, o autor confirmava a presença popular na oposição ao miguelismo e, em decorrência, a favor da Monarquia constitucional, muito provavelmente para contrapor-se a algo que era evidente aos contemporâneos dos acontecimentos: a enorme base social e popular do miguelismo.

Derrotados os revolucionários do Porto, a oposição a D. Miguel, mesmo sujeita à mais feroz perseguição, seguiu firme em todo o país. Enquanto no exílio e, mais tarde, na Ilha Terceira, forjava-se a resistência oficial ao regime, sob a liderança de D. Pedro, pessoas humildes, oficiais mecânicos, caixeiros cerravam uma luta cotidiana e sem tréguas ao usurpador do Trono. Nos quadros seguintes, o item "ocupação" confirma, também para os estrangeiros, que a luta antimiguelista contava com apoio popular.

\section{Os espanhóis}

No conjunto dos processos políticos de Lisboa, predominam os espanhóis, em uma tendência que confirma os laços que uniam, na Península, os liberais de diversos matizes contra as tentativas de restauração do absolutismo em Portugal e na Espanha.

Quadro 1 - Espanhóis que aparecem nos processos políticos

\begin{tabular}{|c|c|c|c|}
\hline No & Nome & Ocupação & Acusação \\
\hline 1 & Ângelo Peres Bolivar & Estudante & Desafeto ao governo \\
\hline 2 & $\begin{array}{l}\text { Ângelo Rodrigues } \\
\text { Furtado }\end{array}$ & Caixeiro viajante & Motivos políticos \\
\hline 3 & $\begin{array}{l}\text { Domingos Rodrigues } \\
\text { de Mendonça Centeno }\end{array}$ & Comerciante & $\begin{array}{l}\text { Frequentar clubes } \\
\text { revolucionários }\end{array}$ \\
\hline 4 & Estevão Afonso & Lavrador & Dar “vivas” à constituição \\
\hline 5 & Francisco Marques & Proprietário & Desafeto ao governo \\
\hline 6 & João Pires & Não consta & $\begin{array}{l}\text { Manter correspondência } \\
\text { com refugiados do Porto na } \\
\text { Espanha }\end{array}$ \\
\hline 7 & Miguel Garcia & Pedreiro & Desafeto ao governo \\
\hline 8 & Manuel José Luciano & Boticário & Desafeto ao governo \\
\hline 9 & $\begin{array}{l}\text { Francisco Gallan } \\
\text { Tabuença }\end{array}$ & Negociante & Desafeto ao governo \\
\hline 10 & Francisco Sancho & Negociante & Desafeto ao governo \\
\hline 11 & $\begin{array}{l}\text { Miguel Joaquim de } \\
\text { Neiva Leão }\end{array}$ & $\begin{array}{l}\text { Alferes do exército } \\
\text { espanhol }\end{array}$ & Desafeto ao governo \\
\hline 12 & $\begin{array}{l}\text { Isidro Romão de Neiva } \\
\text { Leão }\end{array}$ & $\begin{array}{l}\text { Alferes do exército } \\
\text { espanhol }\end{array}$ & Desafeto ao governo \\
\hline 13 & Romão Gonçalves & Boleeiro & Desafeto ao governo \\
\hline
\end{tabular}




\begin{tabular}{|c|c|c|c|}
\hline 14 & Francisco Gomes & Jornaleiro & $\begin{array}{l}\text { Espalhar notícias } \\
\text { tendenciosas }\end{array}$ \\
\hline 15 & Antônio Garcia & Pedreiro & $\begin{array}{l}\text { Participar de motim na } \\
\text { Cadeia da Corte }\end{array}$ \\
\hline 16 & $\begin{array}{l}\text { Dr. Francisco de Paula } \\
\text { Romero Flores }\end{array}$ & Médico & $\begin{array}{l}\text { Proferir palavras ofensivas } \\
\text { contra o monarca }\end{array}$ \\
\hline 17 & Francisco Garcia & Negociante & $\begin{array}{l}\text { Passar gêneros aos } \\
\text { revolucionários do Porto }\end{array}$ \\
\hline 18 & $\begin{array}{l}\text { Joaquim Neves de } \\
\text { Avilez }\end{array}$ & Mercador & $\begin{array}{l}\text { Ser partidário do regime } \\
\text { liberal }\end{array}$ \\
\hline 19 & $\begin{array}{l}\text { Joaquim das Neves } \\
\text { Avilez }\end{array}$ & Ferrador & $\begin{array}{l}\text { Ser partidário do regime } \\
\text { liberal }\end{array}$ \\
\hline 20 & Joaquim Inácio Pereira & $\begin{array}{l}\text { Vice-cônsul } \\
\text { da Espanha e } \\
\text { negociante }\end{array}$ & Participar da revolta de Faro \\
\hline 21 & Manuel de Plassa & Espingardeiro & Desafeto ao governo \\
\hline 22 & José Igreja & Trabalhador & Dar vivas a D. Pedro I \\
\hline 23 & Diego Prieto & $\begin{array}{l}\text { Caixeiro de uma } \\
\text { casa de pasto }\end{array}$ & Desafeto ao governo \\
\hline 24 & Padre Rafael Cardenas & Religioso & Ser exaltado liberal \\
\hline 25 & Pedro José Martins & Porteiro & Desafeto ao governo \\
\hline 26 & João Teixeira de Freitas & $\begin{array}{l}\text { Vice-cônsul da } \\
\text { Espanha }\end{array}$ & $\begin{array}{l}\text { Participar de eventos } \\
\text { revolucionários em Lagos }\end{array}$ \\
\hline 27 & Rodrigues Sentena & Caixeiro & Desafeto ao governo \\
\hline 28 & Manuel Maria & Negociante & Desafeto ao governo \\
\hline 29 & Manuel Pires & Sapateiro & $\begin{array}{l}\text { Participar dos eventos } \\
\text { revolucionários da Vila Real } \\
\text { de Santo Antônio }\end{array}$ \\
\hline 30 & Miguel Seriol & Tanoeiro & $\begin{array}{l}\text { Participar dos eventos } \\
\text { revolucionários da Vila Real } \\
\text { de Santo Antônio }\end{array}$ \\
\hline 31 & Manuel Saballa & Tendeiro & $\begin{array}{l}\text { Proferir expressões } \\
\text { sediciosas e ofensivas }\end{array}$ \\
\hline 32 & Miguel Vasque & $\begin{array}{l}\text { Proprietário de } \\
\text { uma casa de povo }\end{array}$ & Desafeto ao governo \\
\hline 33 & $\begin{array}{l}\text { D. Nicolau Moral de La } \\
\text { Torre }\end{array}$ & Médico & $\begin{array}{l}\text { Participar de eventos } \\
\text { revolucionários em Lagos }\end{array}$ \\
\hline 34 & D. Pedro Bosso & Escrivão & Ser agente revolucionário \\
\hline 35 & José Velasco Lousada & Escrivão & Ser agente revolucionário \\
\hline 36 & D. Filipe Carrasco & $\begin{array}{l}\text { Ajudante do } \\
\text { Estado Maior }\end{array}$ & Ser agente revolucionário \\
\hline 37 & $\begin{array}{l}\text { D. Antônio Maria } \\
\text { Geneves }\end{array}$ & $\begin{array}{l}\text { Capitão de } \\
\text { infantaria }\end{array}$ & Ser agente revolucionário \\
\hline 38 & D. Francisco Igualada & $\begin{array}{l}\text { Capitão de } \\
\text { caçadores }\end{array}$ & Ser agente revolucionário \\
\hline
\end{tabular}




\begin{tabular}{|c|c|c|c|}
\hline 39 & D. João Garcia & $\begin{array}{l}\text { Quartel mestre de } \\
\text { cavalaria }\end{array}$ & Ser agente revolucionário \\
\hline 40 & D. João Gil & $\begin{array}{l}\text { Tenente do } \\
\text { Exército }\end{array}$ & Ser agente revolucionário \\
\hline 41 & Romão Pires da Rocha & Cozinheiro & $\begin{array}{l}\text { Ser partidário do regime } \\
\text { liberal }\end{array}$ \\
\hline 42 & $\begin{array}{l}\text { Sebastião Garcia } \\
\text { Barroso }\end{array}$ & Ferrador & $\begin{array}{l}\text { Proferir palavras sediciosas e } \\
\text { ofensivas contra D. Miguel }\end{array}$ \\
\hline 43 & $\begin{array}{l}\text { D. Vicente Segurado de } \\
\text { Meneses }\end{array}$ & $\begin{array}{l}\text { Tenente-coronel } \\
\text { do Exército }\end{array}$ & $\begin{array}{l}\text { Ser partidário do regime } \\
\text { liberal }\end{array}$ \\
\hline 44 & Padre Vicente Cardoso & Religioso & $\begin{array}{l}\text { Ser partidário do regime } \\
\text { liberal }\end{array}$ \\
\hline 45 & D. Álvaro & Não consta & Desafeto ao governo \\
\hline 46 & Vítor Del Pino & Negociante & $\begin{array}{l}\text { Participar de motim na } \\
\text { cadeia }\end{array}$ \\
\hline
\end{tabular}

Fonte: Processos políticos do reinado de D. Miguel. Fundo dos feitos findos do Arquivo Nacional da Torre do Tombo (ANTT).

Dos 46 espanhóis listados e de ocupação definida, 11 desenvolviam atividades comerciais. Mesmo sabendo-se da imprecisão dos registros, pode-se supor que, dos 11, oito seriam negociantes de grosso trato (seis negociantes, um comerciante e um mercador). Os demais estariam à frente de pequenos negócios, como no caso do proprietário de uma casa do povo, do caixeiro viajante e do tendeiro.

Pelo menos em um caso fica evidente que a atividade do comércio poderia promover o trânsito entre a Espanha e Portugal. Francisco Garcia, comerciante espanhol, foi preso com vários portugueses sob a acusação de, no Rossio de São Roque, em Serpa, "passar com vários animais carregados de gêneros" destinados aos liberais refugiados na Espanha. Não se pode afirmar, porém, nesse caso, que tenham prevalecido os interesses comerciais, as filiações políticas ou os dois conjuntamente. ${ }^{22}$

Os trabalhadores, a "gente do povo", cuja participação na resistência ao regime implantado por D. Miguel era justamente o que Serrão Veloso insistia em comprovar, perfaziam dez dos implicados: um boleeiro; um jornaleiro; um ferrador; um lavrador; dois pedreiros; um espingardeiro; um sapateiro; um tanoeiro e um cozinheiro.

As classificações, assim como a identificação das ocupações nas hierarquias sociais, constituem-se em aproximações, apenas, da realidade que se quer examinar. Optou-se por considerar como pertencente ao serviço público o único escrivão encontrado, assim como o porteiro de Veiros e os dois vice-cônsules da Espanha. Os dois últimos eram acusados de participar de

${ }^{22}$ ANTT, Maço 28, n. 2. 
revoltas em Faro e Lagos e um deles, Joaquim Inácio Pereira, foi expulso do Reino e condenado, no caso de retorno a Portugal, ao degredo para "um dos lugares da África". 23

O estudante, o proprietário, o boticário, os dois religiosos e os dois médicos encontrados na lista podem ser considerados pertencentes a uma camada social intermediária.

Um grupo bem representado entre os implicados é o dos militares. Foram localizados, na documentação, dois alferes do exército espanhol e cinco militares de alta patente: D. Filipe Carrasco, ajudante do Estado-Maior, natural de Cádiz; D. Antônio Maria Geneves, capitão de infantaria; natural de Zafra; D. Francisco Igualada, capitão de caçadores, natural de Málaga; D. João Garcia, quartel mestre de cavalaria, natural de Santander, e D. João Gil, tenente do exército, natural da Catalunha. Todos esses eram refugiados espanhóis do depósito de S. Francisco de Paula e presos, no ano de 1829, no Castelo de S. Jorge, “acusados de agentes revolucionários e distribuidores de proclamações revolucionárias". ${ }^{4}$

\section{Os galegos}

De acordo com Mirian Halpern Pereira, estudos sobre a história da Galícia mostram que o apoio da nobreza a D. Carlos gravitou em torno de 40,5\% e o do clero alcançou cerca de $40 \%$, porcentagens inferiores ao que se verificou em relação a D. Miguel. O carlismo também teria contado com apoio popular, mas os estudos são incipientes, coincidindo com o que se apontou para o caso da Espanha. Ainda de acordo com a autora, a adesão popular ao carlismo parece ter sido superestimada.

Os dados de que dispomos informam sobre o outro lado, o daqueles que se opuseram ao absolutismo. Nesse caso, não contra o carlismo, mas processados por serem acusados de se oporem ao rei absoluto D. Miguel.

Quadro 2 - Galegos que aparecem nos processos

\begin{tabular}{llll} 
No & Nome & Ocupação & Acusação \\
\hline 1 & Bento Pires & $\begin{array}{l}\text { Moço de fretes } \\
\text { Caixeiro de um } \\
\text { armazém de } \\
\text { vinhos }\end{array}$ & $\begin{array}{l}\text { Desafeto ao governo } \\
\text { Divulgação de papéis } \\
\text { sediciosos }\end{array}$ \\
\hline 3 & Miguel Ventura & Alfaiate & Manter conversas sobre \\
4 & $\begin{array}{l}\text { Francisco Antônio de } \\
\text { Barros }\end{array}$ & Aguadeiro & Desafeto ao governo \\
\hline
\end{tabular}

$\overline{{ }^{23} \text { ANTT, Maço 63, n. } 3}$

${ }^{24}$ ANTT, Maço 77, n. 2 B. 


\begin{tabular}{|c|c|c|c|}
\hline 5 & $\begin{array}{l}\text { Francisco Antônio } \\
\text { Ponce de León }\end{array}$ & Comerciante & $\begin{array}{l}\text { Ser exaltado liberal e } \\
\text { pedreiro livre }\end{array}$ \\
\hline 6 & Francisco Espinheira & Moço de forno & $\begin{array}{l}\text { Preso por cantar o hino } \\
\text { constitucional }\end{array}$ \\
\hline 7 & Francisco Espinheira & $\begin{array}{l}\text { Alquilador de } \\
\text { reges }\end{array}$ & Desafeto ao governo \\
\hline 8 & Bento Marinho & Feitor de cocheiras & $\begin{array}{l}\text { Ser afeiçoado ao regime } \\
\text { liberal }\end{array}$ \\
\hline 9 & Francisco Piteira & Padeiro & Desafeto ao governo \\
\hline 10 & Francisco Prado & $\begin{array}{l}\text { Servente de } \\
\text { iluminação da } \\
\text { cidade }\end{array}$ & Desafeto ao governo \\
\hline 11 & Antônio Martins & Moço de fretes & $\begin{array}{l}\text { Proferir blasfêmias contra } \\
\text { D. Miguel }\end{array}$ \\
\hline 12 & $\begin{array}{l}\text { Padre Francisco } \\
\text { Rodrigues Cardeira }\end{array}$ & Prior do Samouco & Proferir gritos subversivos \\
\hline 13 & João Igreja & Negociante & $\begin{array}{l}\text { Ser partidário do regime } \\
\text { liberal }\end{array}$ \\
\hline 14 & João Luís Alonço & $\begin{array}{l}\text { Armazenista de } \\
\text { azeite }\end{array}$ & $\begin{array}{l}\text { Falar mal do governo de } \\
\text { D. Miguel }\end{array}$ \\
\hline 15 & João Gonçalves & Criado de servir & $\begin{array}{l}\text { Falar mal do governo de } \\
\text { D. Miguel }\end{array}$ \\
\hline 16 & João Semécio & $\begin{array}{l}\text { Capataz do } \\
\text { chafariz das } \\
\text { Janelas Verdes }\end{array}$ & $\begin{array}{l}\text { Proferir expressões } \\
\text { sediciosas }\end{array}$ \\
\hline 17 & Joaquim José Leite & $\begin{array}{l}\text { Mercador de } \\
\text { lençaria }\end{array}$ & Desafeto ao governo \\
\hline 18 & Vicente Rodrigues & Boleeiro & $\begin{array}{l}\text { Participar de reuniões } \\
\text { políticas }\end{array}$ \\
\hline 19 & José António Pires & Criado de servir & Cantar o hino constitucional \\
\hline 20 & João Antônio Trancoso & Criador de servir & Cantar o hino constitucional \\
\hline 21 & José Bento Serra & Barbeiro & $\begin{array}{l}\text { Proferir expressões } \\
\text { sediciosas }\end{array}$ \\
\hline 22 & André da Silva & Aguadeiro & Desafeto ao governo \\
\hline 23 & Agostinho Esteves & $\begin{array}{l}\text { Moço da } \\
\text { iluminação da } \\
\text { cidade de Lisboa }\end{array}$ & Passar papéis sediciosos \\
\hline 24 & José Francisco Covas & Criado de servir & $\begin{array}{l}\text { Espalhar notícias } \\
\text { tendenciosas }\end{array}$ \\
\hline 25 & José Serra & Padeiro & $\begin{array}{l}\text { Proferir expressões } \\
\text { sediciosas e ofensivas }\end{array}$ \\
\hline 26 & $\begin{array}{l}\text { Julião do Bem } \\
\text { Rodrigues }\end{array}$ & Caldereiro & Dar vivas a D. Pedro \\
\hline
\end{tabular}




\begin{tabular}{|c|c|c|c|}
\hline 27 & Manuel de Andrade & Alfaiate & Escrever uma carta política \\
\hline 28 & Manuel de Araújo & $\begin{array}{l}\text { Dono de loja de } \\
\text { bebida }\end{array}$ & $\begin{array}{l}\text { Ser fervoroso partidário do } \\
\text { regime liberal }\end{array}$ \\
\hline 29 & Manuel Bento Alves & $\begin{array}{l}\text { Criado de farda do } \\
\text { conde de Porto } \\
\text { Santo }\end{array}$ & $\begin{array}{l}\text { Afirmar que D. Miguel não } \\
\text { era rei e sim D. Pedro. }\end{array}$ \\
\hline 30 & Manuel Moreira Garcia & Merceeiro & $\begin{array}{l}\text { Ser portador de livros } \\
\text { sediciosos }\end{array}$ \\
\hline 31 & Manuel de Pinho & Cozinheiro & Cantar o hino constitucional \\
\hline 32 & Martinho de Amoedo & Não consta & $\begin{array}{l}\text { Proferir expressões contra D. } \\
\text { Miguel }\end{array}$ \\
\hline 33 & $\begin{array}{l}\text { Pedro António de } \\
\text { Frágoas }\end{array}$ & Criado & $\begin{array}{l}\text { Afirmar que "jogaria bola } \\
\text { com a cabeça de D. Miguel" }\end{array}$ \\
\hline 34 & $\begin{array}{l}\text { D. João Bernardino de } \\
\text { Leira }\end{array}$ & $\begin{array}{l}\text { Capitão de } \\
\text { Infantaria }\end{array}$ & Ser agente revolucionário \\
\hline 35 & Pedro Bento d'Outrilho & Criado & $\begin{array}{l}\text { Participação nos tumultos } \\
\text { da rebelião do Regimento de } \\
\text { Infantaria } 2\end{array}$ \\
\hline 36 & Tiago Aires & Conserveiro & Cantar o hino constitucional \\
\hline 37 & Vicente Cardoso & Aguadeiro & Cantar o hino constitucional \\
\hline
\end{tabular}

Fonte: Processos políticos do Reinado de D. Miguel. Fundo dos feitos findos do Arquivo Nacional da Torre do Tombo (ANTT).

Entre os galegos, predominam as ocupações que revelam a extração popular desse grupo.

Dos 37 processados provenientes da região da Galícia, cinco estavam ligados ao comércio. Aparecem apenas um negociante, um mercador, um comerciante, um dono de loja de bebidas e um último como merceeiro.

Se uma ocupação como a de aguadeiro sugere algum tipo de comércio, sem dúvida trata-se de pequenos serviços, típicos das áreas urbanas. Os três aguadeiros constantes nas listas certamente se aproximam, socialmente, daqueles que exerciam profissões típicas do ofício mecânico, como o ferrador, o barbeiro e os alfaiates, esses últimos em número de três. No que se poderia classificar como setor de serviços, o destaque cabe aos criados de servir que ocupam categoria que, individualmente, reúne o maior número dos processados galegos. Quanto à ocupação inferior, exercida pelos segmentos das camadas de menor extração social, ela nos mostra o fato de que cabia também aos pretos o desempenho desse tipo de tarefa. A exceção aqui talvez caiba ao criado de farda do conde de Porto Santos, Manuel Bento Alves, "preso junto ao Palácio Real da Ajuda, por afirmar que D. Miguel não era Rei, mas sim D. Pedro". 25

${ }^{25}$ ANTT, Maço 69, n. 15 . 
Apenas um militar aparece na documentação, um capitão de infantaria, bem como um único religioso, o prior de Samouco, o padre Francisco Rodrigues Cardeira.

\section{Outras nacionalidades}

Como já mencionado, principalmente a partir da Revolução Francesa e em clara oposição à política da Santa Aliança, observou-se a união de militantes em torno das ideias liberais, da superação da antiga ordem, de natureza internacionalista, de que é exemplo, já citado, a Assembleia de Constitucionais Europeus.

\section{Identificar personagens que, com graus diferentes de envolvimento, lutaram contra o regime absolutista de D. Miguel e puseram-se, muitos deles, em defesa do constitucionalismo, pode contribuir para o entendimento da formação das nações modernas}

No atual estágio da pesquisa, ainda não é possível afirmar que pelo menos alguns dos incriminados de outras nacionalidades participavam dessa sociedade secreta. O que os dados permitem depreender é que vários foram suspeitos de militarem contra o absolutismo imposto por D. Miguel nos anos entre 1828 e 1834. A se destacar o fato de que cinco deles, com predomínio dos naturais de Gênova e da Inglaterra, foram acusados, em diferentes devassas abertas em Alenquer, Entremoz e Vila Real de Santo Antônio, de participarem de rebeliões. ${ }^{26}$ Se tomaram parte nos acontecimentos, algo difícil de afirmar a partir apenas de uma fonte repressiva, foram bem além de entoar o hino constitucional ou blasfemar contra D. Miguel. Atitudes distinguíveis apenas aos olhos de hoje, mas praticamente indistintas e igualmente corajosas no contexto de um regime absolutista ou totalitário.

Dos estrangeiros constantes na documentação, além de três dos naturais de Gênova, dos quais dois eram irmãos, também era negociante o cubano Manoel Mimoso. Se somarmos a atividade de cambista a essa categoria, é ela que prevalece.

Chama a atenção o processo movido contra João Miley Doile, coronel do exército britânico, natural da Irlanda, preso perto de Leiria juntamente com D. José Maria de Sousa Coutinho, dois criados e um guia, "por suspeita de se querer ir juntar aos rebeldes do Porto". D. José Maria de Sousa Coutinho era filho de D. Rodrigo de Sousa Coutinho, o então já falecido todo poderoso secretário

\footnotetext{
${ }^{26}$ A presença de ingleses nos processos de Lisboa, muito provavelmente, não é representativa da militância dos liberais dessa nacionalidade contra o regime de D. Miguel, a exemplo do que se observou na cidade do Porto, em maio de 1828. De acordo com António Barros Cardoso (2006, p.239-280), os britânicos gozavam de imunidades que dificultavam a ação repressiva das autoridades portuguesas.
} 
de Estado dos Negócios da Marinha e Domínios Ultramarinos do regente D. João, e de D. Gabriela Asinari de S. Marsan, condes de Linhares. Por Acórdão de 6 de setembro de 1828, foi confirmada a sentença do conservador da Nação Britânica e João Miley Doile foi condenado a "sair do Reino no prazo de oito dias", sendo "conduzido preso para o navio que o levasse". ${ }^{27}$ D. José Maria de Sousa Coutinho passou a responder o processo em separado sob a mesma acusação de pretender "juntar-se aos rebeldes do Porto", situação agravada por ter-se encontrado, entre suas coisas, um "manifesto revolucionário". Nem todos os grandes de Portugal apoiavam o retorno à antiga ordem, defendido por D. Miguel. ${ }^{28}$

Quadro 3 - Processados políticos de diversas naturalidades

\begin{tabular}{|c|c|c|c|c|}
\hline Nação & No & Nome & Ocupação & Acusação \\
\hline \multirow[t]{5}{*}{ Itália } & 1 & $\begin{array}{l}\text { Domingo } \\
\text { Chiapori } \\
\text { d’Ambrosi }\end{array}$ & Negociante & $\begin{array}{l}\text { Envolvimento na } \\
\text { revolta do Alenquer }\end{array}$ \\
\hline & 2 & $\begin{array}{l}\text { João Maria } \\
\text { Guidotti }\end{array}$ & Negociante & $\begin{array}{l}\text { Envolvimento na } \\
\text { revolta do Alenquer }\end{array}$ \\
\hline & 3 & $\begin{array}{l}\text { José António } \\
\text { Guidotti }\end{array}$ & Negociante & $\begin{array}{l}\text { Envolvimento na } \\
\text { revolta do Alenquer }\end{array}$ \\
\hline & 4 & Paulo d’Ambrósio & Não consta & Por motivos políticos \\
\hline & 5 & Tomás Tasso & Cambista & $\begin{array}{l}\text { Proferir expressões } \\
\text { sediciosas }\end{array}$ \\
\hline \multirow[t]{2}{*}{ França } & 1 & José Claro & Pintor & Desafeto ao governo \\
\hline & 2 & Pierre Suére & Cabeleireiro & $\begin{array}{l}\text { Proferir palavras } \\
\text { sediciosas }\end{array}$ \\
\hline \multirow[t]{2}{*}{ Inglaterra } & 1 & João Lord & $\begin{array}{l}\text { Administrador } \\
\text { do comerciante } \\
\text { Redon }\end{array}$ & $\begin{array}{l}\text { Envolvimento na } \\
\text { revolta de Entremoz }\end{array}$ \\
\hline & 2 & Luís Cassar & Não consta & $\begin{array}{l}\text { Envolvimento na } \\
\text { revolta de S. Antônio }\end{array}$ \\
\hline \multirow[t]{2}{*}{ Irlanda } & 1 & Estevão Sinnott & Moleiro & Desafeto ao governo \\
\hline & 2 & João Miley Doile & $\begin{array}{l}\text { Coronel do } \\
\text { Exército Britânico }\end{array}$ & $\begin{array}{l}\text { Querer juntar-se aos } \\
\text { rebeldes do Porto }\end{array}$ \\
\hline Gibraltar & 1 & $\begin{array}{l}\text { João José de } \\
\text { Frágoas }\end{array}$ & $\begin{array}{l}\text { Escrivão interino } \\
\text { da Câmara de } \\
\text { Olhão }\end{array}$ & $\begin{array}{l}\text { Por haver escrito o } \\
\text { auto de aclamação } \\
\text { de D. Pedro }\end{array}$ \\
\hline Cuba & 1 & Manoel Mimoso & Negociante & Insultos ao regime \\
\hline \multicolumn{5}{|c|}{$\begin{array}{l}\text { Fonte: Processos políticos do Reinado de D. Miguel. Fundo dos feitos findos do Arquivo Nacional da Torre } \\
\text { do Tombo (ANTT). }\end{array}$} \\
\hline \multicolumn{5}{|c|}{$\begin{array}{l}{ }^{27} \text { ANTT, Maço 63, n. } 1 . \\
{ }^{28} \text { ANTT, Maço 63, n. } 2 .\end{array}$} \\
\hline
\end{tabular}




\section{Considerações finais}

Em O primeiro homem, o último de um dos seus mais comoventes livros, até mesmo pelo inacabamento, em decorrência de sua morte em um acidente trágico, Albert Camus (1994, p. 148), descreve a experiência de sua infância na Argélia francesa. Na frase emprestada da obra para compor o título deste artigo, o autor sintetiza o resultado da crise do colonialismo tardio para as populações dos domínios europeus na África: "cidadãos teóricos de uma nação imprecisa”.

A frase parece caber muito bem no contexto de crise do Antigo Regime na Europa e, com ele, da paulatina superação dos sistemas imperiais e emergência dos Estados Nacionais Modernos.

No caso dos estrangeiros que lutaram na resistência ao regime implantado por D. Miguel, em defesa do constitucionalismo e de bandeiras liberais, talvez a ideia da imprecisão da nação à qual pertenciam seja mais acentuada, pois, àquela altura, e ao contrário da ocasião em que escreve Camus, sequer na Europa as nações apresentavam contornos bem definidos. O que fica mais claro para os "italianos" ou para os "alemães" processados, os quais, só raramente, aparecem designados dessa forma, prevalecendo suas cidades de origem. E o que dizer do "cubano" Manoel Mimoso, uma vez que Cuba só se tornaria independente da Espanha em 1898?

Com isso, não se quer negar a existência de um sentimento de pertencimento, talvez mais evidente na Península Ibérica, provavelmente o prolongamento, no tempo, do que François-Xavier Guerra denominou de "patriotismo imperial" (Guerra, 1999/2000, p.9-30) e que seria característico dos movimentos que antecederam os processos de emancipação na América Hispânica. Talvez a constatação da persistência desse sentimento explique, pelo menos em parte, a permanência do projeto de reunificação, principalmente do Império luso-brasileiro, no interior de alguns grupos sociais. No caso espanhol, a experiência imperial, ainda recente, talvez contribuísse para que a proposta de apoio a um rei comum a Espanha e a Portugal soasse como uma solução palatável aos grupos liberais, mesmo que se encontrassem à frente do processo de construção do Estado Nacional Moderno.

\section{Referências bibliográficas}

ANDERSON, Benedict. Comunidades Imaginadas. São Paulo: Companhia das Letras, 2008. BRANCATO, Braz Augusto Aquino. Don Pedro I de Brasil, possible rey de España: una conspiración liberal. Porto Alegre: EDIPUCRS, 2014.

BURKE, Peter. Cultura popular na Idade Moderna: 1500-1800. São Paulo: Companhia das Letras, 2009.

CAMUS, Albert. O primeiro homem. Rio de Janeiro: Nova Fronteira, 1994.

CANAL, Jordi. Carlismo y contrarrevolução. La Aventura de la Historia, n. 77, 2005. Disponível em: http://dialnet.unirioja.es/servlet/ejemplar? codigo=108956. Acesso em: 11 jan. 2015.

CARDOSO, António Barros. Liberais e absolutistas no Porto (1823-1829). In: ESTUDOS em Homenagem ao Professor Doutor José Marques. Universidade do Porto, Faculdade de Letras, 2006. p. 239-280. 
CARTAS de Valentim Marcellino dos Santos ao Sr. Francisco Jerônimo da Silva acerca da Archi-confraria do Santíssimo Coração de Maria. Porto Typografia de Sousa \& Faria. Rua Nova do Almada, n.139, s.d. Biblioteca Geral da Universidade de Coimbra.

CASCÃO, Rui. A revolta de maio de 1828 na Comarca de Coimbra. Contribuição para uma sociologia da Revolução Liberal. Revista de História das Ideias, vol. 7, 1985.

CATROGA, Fernando. Pátria, nação e nacionalismo. In: SOBRAL, José Manuel; VALA, Jorge (Ed.). Identidade nacional, inclusão e exclusão social. Lisboa: ICS, 2010.

COLEÇÃO de listas que contêm os nomes das pessoas que ficaram pronunciadas e sumários a que mandou proceder o Governo Usurpador depois da heroica contrarrevolução que arrebentou na mui nobre cidade do Porto em 16 de maio de 1828, nas quais se faz menção do destino que a Alçada, criada pelo mesmo governo para as julgar, deu a cada uma delas. Porto: Tipografia de Viúva Álvares Ribeiro \& Filho, 1833.

COSTA, Wilma Peres. Entre tempos e mundos: Chateaubriand e a outra América. Almanack Braziliense, São Paulo, n.11, 2010. p. 5-25.

FERREIRA, Maria de Fátima Sá e Melo. Rebeldes e insubmissos: resistências populares ao liberalismo (1834-1844). Porto: Afrontamento, 2002.

GEERTZ, Clifford. A interpretação das culturas. Rio de Janeiro: LTC, 1998.

GONÇALVES, Andréa Lisly. A luta de brasileiros contra o miguelismo em Portugal (1828-1834): o caso do homem preto Luciano Augusto. Revista Brasileira de História, vol. 33, 2013. p. 211-234. GONÇALVES, Andréa Lisly. Aspectos da história e da historiografia sobre o Brasil e Portugal das primeiras décadas do século XIX. História da Historiografia, vol. 10, 2012. p. 32-55.

GUERRA, François-Xavier. A nação na América espanhola: a questão das origens. Maracanan, vol. 1, n. 1, 1999/2000. p. 9-30.

GUERRA, François-Xavier. Conocimiento y representaciones contemporáneas del proceso de continuidad y ruptura. In: DAMAS, Germán Carrera; LOMBARDI, John V. (Ed.). La crisis estructural de las sociedades implantadas. Madri: Editorial Trotta, 2007. p. 429-447.

HESPANHA, António Manuel. Guiando a mão invisível. Direitos, Estado e lei no liberalismo monárquico português. Coimbra: Almedina, 2004.

LIMA, Jorge Hugo Pires de. Processos políticos do reinado de D. Miguel. Coimbra: 1972.

LINZ, Juan. Regimes autoritários. In: PINHEIRO, Paulo Sérgio (ed.). O Estado autoritário e os movimentos populares. Rio de Janeiro: Paz e Terra, 1980.

LOUSADA, Maria Alexandre. O Miguelismo (1828-1834). O discurso político e o apoio da nobreza titulada. Provas de aptidão pedagógica e capacidade científica apresentadas na Faculdade de Letras da Universidade de Lisboa, Trabalho de síntese, Lisboa, 1987.

LOUSADA, Maria Alexandre; FERREIRA, Maria de Fátima Sá e Melo. D. Miguel. Lisboa: Círculo de Leitores e Centro de Estudos dos Povos e culturas de expressão portuguesa, 2009.

MANNHEIM, Karl. Essays on sociology and social psychology. Nova York: 1953.

PAQUETE, Gabriel. The Brazilian Origins of the 1826 Portuguese Constitution. European History Quarterly, vol. 41, n. 3, 2011.p. 444-471.

PEDREIRA, Jorge; COSTA, Fernando Dores. D. João VI. Lisboa: Círculo de Leitores/Centro de Estudos dos Povos e Culturas de Expressão Portuguesa, 2006.

PEREIRA, Mirian Halpern. Do Estado liberal ao Estado providência: um século em Portugal. São Paulo: Edusc, 2012.

PERIÓDICO para os bons realistas. Jornal Histórico, político e noticioso, n. 1, terça-feira, 10 de junho, 1828. Na nova Impressão Silviana. Ano de 1828. Com licença. Travessa da Portaria das Freiras de Santa Ana.

RAMOS, Rui; SOUSA, Bernardo; MONTEIRO, Nuno Gonçalo (Coord.). História de Portugal. Lisboa: A esfera dos Livros, 2009.

RÚJULA, Pedro. Acerca de la especificidad del carlismo. Gerónimo de Uztariz, n. 9/10, 1994. SUANZES-CARPEGNA, Joaquim Varela. O constitucionalismo espanhol e português durante a primeira metade do século XIX (um estudo comparado). História Constitucional, n. 11, 2010. Disponível em: http://historiaconstitucional.com. 